\title{
Studies of the species barrier between Drosophila subobscura and D. madeirensis I. The genetics of male hybrid sterility
}

\author{
MAHNAZ KHADEM \& COSTAS B. KRIMBAS \\ Department of Genetics, Agricultural University of Athens, lera Odos 75 Athens 118-55, Greece
}

\begin{abstract}
The genetics of hybrid male sterility between Drosophila subobscura and D. madeirensis were studied with the help of 20 markers in backcross males. A major effect resides in the sex chromosomes: backcross males with the $\mathrm{X}$ and $\mathrm{Y}$ of different origin (mad X-sub $\mathrm{Y}$ or sub X-mad $\mathrm{Y}$ ) have very small and empty testes. In compatible combinations testes are of normal size but males may be sterile or fertile depending on the genetic constitution of their autosomes. Six autosomal factors affecting hybrid male fertility could be postulated. This estimation is based on the assumption of the absence of interaction between viability and fertility. The presence and the mode of such interaction may modify the number of sterility factors.
\end{abstract}

Keywords: Drosophila, hybrid sterililty, sex chromosomes, species barrier.

\section{Introduction}

Several alternative theories and mechanisms have been advanced to describe and explain the genesis of species (for review see White, 1978; Wright, 1982; Barton \& Charlesworth, 1984; Carson \& Templeton, 1984). On the other hand there are few experimental data available concerning the nature of these processes and still fewer cases have been analysed in detail. The collection of more data requires the use of biological material suited to detailed analysis.

The Drosophila species are favourable material to study the evolution of reproductive isolation. A technique is available from the pioneering work of Dobzhansky, in 1936, for the investigation of the genetics of $F_{1}$ male sterility when the $F_{1}$ females are fertile. This technique, based on following visible marker loci in backcross males, has been improved, and more studies have been carried out in different species of Drosophila (Coyne, 1984, 1985; Vigneault \& Zouros, 1986; Naviera \& Fontdevila, 1986; Orr, 1987, 1989). In addition to male hybrid sterility, recently some cases of female hybrid sterility have been reported (Orr, 1987, 1989). The results of these studies indicate (see Coyne \& Orr, 1989a) that the usual pathway for the evolution of postzygotic isolation is the early appearance of sterility and inviability in the male hybrids from both reciprocal crosses, followed by the appearance of these abnormalities in female hybrids, which is in accordance with Haldane's rule, formulated in 1922. The detailed study of several cases of postzygotic isolation will eventually provide some evidence on the genetic system(s) mobilized to produce this effect. The answer to this question will shed some light on the evolutionary mechanisms which lead to the creation of species barriers.

In this paper the results of an investigation of two closley related species that belong to the obscura group are reported. For the first time a considerable number of markers is used. We gathered data with the help of 20 genetic markers (cytological, electrophoretic and visible mutants) concerning hybrid male sterility between $D$. madeirensis, a species from Madeira Island, and $D$. subobscura, which has a wide paleartic distribution. Both species are present in Madeira, but only $D$. madeirensis is endemic to it

\section{Materials and methods}

\section{Strains}

The following strains of $D$. subobscura were used, $\mathrm{Ku}$ (Kusnacht), 8 (Crete), ch $\mathrm{cu}$ (cherry eyes-curled wings), $p p p l$ (poppy eyes-plexus wings) and $n t$ (net wings). Two monomorphic strains of $D$. madeirensis were also 
Table 1 Genetic constitution of D. subobscura and D. madeirensis strains used in this study. A bracket unites the alternative alleles or gene arrangments for a polymorphic marker. The markers are listed according to the order of their location starting from the distal end of the chromosome (all chromosomes are acrocentric)

\begin{tabular}{|c|c|c|c|c|c|c|c|}
\hline & \multicolumn{6}{|c|}{ D. subobscura } & \multirow[b]{2}{*}{ D. madeirensis } \\
\hline & ku & 8 & ch cu & pp pl & ma int & nt & \\
\hline$A$ inv $16 B C D$ & ST & ST & ST & ST & ST & ST & $\operatorname{mad}$ \\
\hline A antenna colour & dark & dark & dark & dark & dark & dark & light \\
\hline$A$ inv $A 2$ & ST & $\mathrm{A} 2$ & ST & ST & ST & ST & ST \\
\hline A inv MAD1 & ST & ST & $\mathrm{ST}$ & ST & ST & ST & MAD1 \\
\hline U nt & ST & ST & ST & ST & ST & net & ST \\
\hline $\mathbf{U}$ inv $\mathbf{U} 1+2$ & ST & $1+2$ & $\left\{\begin{array}{l}\mathrm{ST} \\
1+2+6\end{array}\right.$ & $\left\{\begin{array}{l}\mathrm{ST} \\
1+2\end{array}\right.$ & ST & $1+2$ & $1+2$ \\
\hline E pl & ST & ST & ST & $\mathrm{pl}$ & ST & ST & ST \\
\hline $\mathbf{E p p}$ & ST & ST & ST & $\mathrm{pp}$ & ST & ST & ST \\
\hline E inv E1 + 2 & ST & $1+2$ & ST & ST & ST & ST & ST \\
\hline E Pept-3 & 1.00 & 1.00 & 1.00 & 1.00 & 1.00 & 1.00 & 1.08 \\
\hline E centromere & sub & sub & sub & sub & sub & sub & $\operatorname{mad}$ \\
\hline $\mathbf{J}$ tip & sub & sub & sub & sub & sub & sub & $\operatorname{mad}$ \\
\hline $\mathbf{J}$ ldh & 1.00 & 1.00 & 1.00 & 1.00 & 1.00 & 1.00 & 1.10 \\
\hline $\mathbf{J} \mathrm{ma}$ & ST & ST & ST & ST & $\mathrm{ma}$ & ST & ST \\
\hline $\mathbf{J}$ int & ST & $\mathrm{ST}$ & ST & ST & int & ST & ST \\
\hline $\mathbf{J}$ inv $\mathbf{J} 1$ & ST & $\mathrm{J} 1$ & $\{\mathrm{ST}$ & $\{\mathrm{ST}$ & ST & $\mathrm{J} 1$ & ST \\
\hline $\mathbf{J}$ centromere & sub & sub & sub & sub & sub & sub & $\operatorname{mad}$ \\
\hline $\mathbf{O}$ inv 03 & ST & $3+4$ & $3+4$ & $\mathrm{ST}$ & $3+4$ & $\mathrm{ST}$ & 3 \\
\hline $\mathrm{OMe}$ & 1.00 & 1.00 & 1.00 & 1.00 & 1.00 & 1.00 & 1.10 \\
\hline $\mathbf{O}$ centromere & sub & sub & sub & sub & sub & sub & $\operatorname{mad}$ \\
\hline
\end{tabular}

used, the details of strains and markers are given in Table 1.

\section{Crosses}

Females of $D$. madeirensis were crossed to $D$. subobscura males; fertile $F_{1}$ female progeny were crossed either to $D$. subobscura or $D$. madeirensis males (all $F_{1}$ males are sterile). The results given in Table 2 include both types of crosses, while Tables 3 and 4 show only the analysis of the backcross males produced by crossing $\mathrm{F}_{1}$ females to $D$. subobscura males. Moreover the results in Table 2 are from direct dissection of 4-5 day-old hybrid males and sperm motility was considered as a measure of fertility. Table 3 shows the tests of viability (departure from 1:1 ratio in total flies). In the case of the electrophoretic and visible mutants the results were obtained directly by counting the backcross males of each category whereas the results in Table 4 were obtained by putting individual backcross males together with virgin females of the parental $D$. subobscura species, and fertility was considered as the ability to produce progeny. This procedure was necessary because all our cytological markers can only be detected in the progeny of the fertile backcross males. The totals in the case of cytological markers are the same in Tables 3 and 4 . They are the same backcross males but at the stage of third instar larvae or pupae.

Each type of cross (using different strains) was performed 2-4 times and the homogeneous results were added up. All together 20 markers were used: 11 polytene chromosomal, six visible and three electrophoretic markers (all listed in Table 1). Some comments should be added to this listing (Table 1), D. subobscura and $D$. madeirensis have different gene arrangements in their $\mathrm{A}(=\mathrm{X})$ and $\mathrm{O}$ chromosomes. Inversions $16 \mathrm{BCD}$ and MAD 1 are specific to $D$. madeirensis and are fixed in it. MAD 1 differs from inversion $\mathrm{A} 1$ of $D$. subobscura, but was confused with it 
Table 2 Backcross males from two backcrosses showing different size of testes and the presence or absence of sperm. All individuals have madeirensis cytoplasm but different combinations of $\mathrm{X}$ and $\mathrm{Y}$ chromosomes. The origin of the $\mathrm{X}$ chromosome is detected by the colour of the antennae, while the origin of the $\mathrm{Y}$ is known from the type of backcross. Incompatible combinations are those that bear $\mathrm{X}$ and $\mathrm{Y}$ from a different origin and display small testes, usually empty. The exception to this incompatibility rule is indicated in the last column, they amount to 4.4 per cent and are interpreted as $\mathrm{X}$ crossover products

\begin{tabular}{|c|c|c|c|c|c|c|}
\hline $\begin{array}{l}\text { Incompatibility in } \\
\text { sex chromosome } \\
\text { combinations }\end{array}$ & $\begin{array}{l}\text { Antennae colour } \\
\text { (chromosome X) }\end{array}$ & $\begin{array}{l}\text { Chromosome } \\
\text { Y }\end{array}$ & Size of testes & Sperm & Number & $\begin{array}{l}\text { Exceptions } \\
\text { to the rule }\end{array}$ \\
\hline \multicolumn{7}{|c|}{$\mathrm{A} /$ Backcross of $\mathrm{F}_{1}$ $\&(\mathrm{mad} \times \mathrm{sub})$ to madeirensis males } \\
\hline Yes & dark (sub) & $\operatorname{mad}$ & very small & absent & 136 & - \\
\hline Yes & dark (sub) & $\operatorname{mad}$ & normal & immotile or absent & 7 & Yes \\
\hline No & white (mad) & $\operatorname{mad}$ & very small & absent & 2 & Yes \\
\hline No & white (mad) & $\operatorname{mad}$ & 1 very small, 1 normal & immotile & 2 & Yes \\
\hline No & white (mad) & $\operatorname{mad}$ & normal & immotile & 43 & - \\
\hline No & white (mad) & $\operatorname{mad}$ & normal & motile & 36 & - \\
\hline \multicolumn{7}{|c|}{ B/Backcross of $F_{1} \wp \wp(\mathrm{mad} \times \mathrm{sub})$ to subobscura males } \\
\hline Yes & white (mad) & sub & very small & absent & 35 & - \\
\hline Yes & white (mad) & sub & small & absent & 2 & - \\
\hline No & $\operatorname{dark}($ sub $)$ & sub & 1 very small, 1 normal & immotile & 2 & Yes \\
\hline No & dark (sub) & sub & 1 very small, normal & motile & 1 & Yes \\
\hline No & $\operatorname{dark}(\mathrm{sub})$ & sub & normal & immotile & 62 & - \\
\hline No & dark (sub) & sub & normal & motile & 35 & - \\
\hline
\end{tabular}

Table 3 The results of chi-squared testing for the departure from one-to-one ratio are reported for the total number of flies (all have 1 d.f.). Any significant departure is indicative of the effect on viability of the region on which the marker is located. In the case of the A chromosome female flies were used

\begin{tabular}{lrrrrrl}
\hline & & Homozygous & Heterozygous & Total & \multicolumn{2}{l}{$\chi^{2}$} \\
\hline Chromosome & $\mathrm{A}$ & & & & & \\
A 16 BCD & $\mathrm{T}$ & 10 & 14 & 24 & 0.66 & $\mathrm{~ns}$ \\
A MAD1 & $\mathrm{T}$ & 13 & 11 & 24 & 0.17 & $\mathrm{~ns}$ \\
A MAD1 + A2 & $\mathrm{T}$ & 13 & 11 & 24 & 0.17 & $\mathrm{~ns}$ \\
Chromosome & $\mathrm{U}$ & & & & & \\
nt & $\mathrm{T}$ & 188 & 193 & 381 & 0.04 & $\mathrm{~ns}$ \\
Chromosome & $\mathrm{E}$ & & & & & \\
pl & $\mathrm{T}$ & 72 & 125 & 197 & 19.82 & $* * *$ \\
pp & $\mathrm{T}$ & 100 & 97 & 197 & 0.02 & $\mathrm{~ns}$ \\
E 1 +2 & $\mathrm{T}$ & 15 & 27 & 42 & 3.52 & $\mathrm{~ns}$ \\
Pept-3 & $\mathrm{T}$ & 180 & 249 & 249 & 10.8 & $* *$ \\
Centromere & $\mathrm{T}$ & 19 & 23 & 42 & 0.38 & $\mathrm{~ns}$ \\
Chromosome & $\mathrm{J}$ & & & & & \\
tip & $\mathrm{T}$ & 25 & 15 & 40 & 3.50 & $\mathrm{~ns}$ \\
ldh & $\mathrm{T}$ & 198 & 231 & 429 & 2.39 & $\mathrm{~ns}$ \\
ma & $\mathrm{T}$ & 1615 & 1667 & 3282 & 0.8 & $\mathrm{~ns}$ \\
int & $\mathrm{T}$ & 625 & 620 & 1245 & 0.02 & $\mathrm{~ns}$ \\
J 1 & $\mathrm{T}$ & 18 & 22 & 40 & 0.4 & $\mathrm{~ns}$ \\
Centromere & $\mathrm{T}$ & 27 & 13 & 40 & 4.9 & $*$ \\
Chromosome & 0 & & & & & \\
03 & $\mathrm{T}$ & 20 & 20 & 40 & 0.00 & $\mathrm{~ns}$ \\
Me & $\mathrm{T}$ & 238 & 191 & 429 & 5.93 & $*$ \\
Centromere & $\mathrm{T}$ & 19 & 21 & 40 & 0.1 & $\mathrm{~ns}$ \\
\hline & & & & & &
\end{tabular}


Table 4 The genetic constitution of fertile $(F)$ backcross males compared to that of sterile (S) males or to the totality of those males $(T)$. In the example of the $X$ chromosome the comparison was made with females. Chi-square testing of the departure from homogeneity between $\mathrm{F}$ and $\mathrm{S}$ (or $\mathrm{F}$ and $\mathrm{T}$ ) is reported (all have 1 d.f.)

\begin{tabular}{|c|c|c|c|c|c|c|}
\hline & & subobscura & madeirensis & Total & $\chi^{2}$ & \\
\hline Chromosome & A & & & & & \\
\hline \multirow[t]{2}{*}{ A 16BCD } & $F$ & 107 & 14 & 121 & & \\
\hline & $\mathrm{T}$ & 10 & 14 & 24 & 14.00 & $* * *$ \\
\hline \multirow[t]{2}{*}{ A MAD1 } & $F$ & 121 & 0 & 121 & & \\
\hline & $\mathrm{T}$ & 13 & 11 & 24 & 54.08 & $* * *$ \\
\hline \multicolumn{2}{|c|}{$\mathrm{A} \mathrm{MAD} 1+\mathrm{A} 2 \mathrm{~F}$} & 33 & 0 & 33 & & \\
\hline & $\mathrm{T}$ & 13 & 11 & 24 & 16.42 & $* * *$ \\
\hline Chromosome & $\mathrm{U}$ & Homozygous & Heterozygous & & & \\
\hline \multirow[t]{2}{*}{$\mathrm{nt}$} & $F$ & 21 & 20 & 41 & & \\
\hline & $S$ & 167 & 173 & 340 & 0.204 & ns \\
\hline $\mathrm{U} 1+2$ & $\mathrm{~F}$ & 28 & 2 & 30 & 22.45 & $* * *$ \\
\hline \multirow{3}{*}{$\begin{array}{l}\text { Chromosome } \\
\text { p1 }\end{array}$} & $\mathrm{E}$ & & & & & \\
\hline & $F$ & 3 & 5 & 8 & & \\
\hline & $\mathrm{S}$ & 27 & 53 & 88 & 0.00 & ns \\
\hline \multirow[t]{2}{*}{$\mathrm{pp}$} & $\mathbf{F}$ & 7 & 10 & 17 & & \\
\hline & $\mathrm{S}$ & 137 & 162 & 299 & 0.25 & ns \\
\hline \multirow[t]{2}{*}{$\mathrm{E} 1+2$} & $F$ & 21 & 10 & 31 & & \\
\hline & $\mathrm{T}$ & 15 & 27 & 42 & 7.45 & $* *$ \\
\hline \multirow[t]{2}{*}{ Pept-3 } & $F$ & 76 & 56 & 132 & & \\
\hline & $\mathbf{S}$ & 246 & 313 & 559 & 8.04 & $* *$ \\
\hline \multirow[t]{2}{*}{ Centromere } & $F$ & 62 & 40 & 102 & & \\
\hline & $\mathrm{T}$ & 19 & 23 & 42 & 3.07 & ns \\
\hline \multirow{3}{*}{$\begin{array}{l}\text { Chromosome } \\
\quad \text { tip }\end{array}$} & $\mathbf{J}$ & & & & & \\
\hline & $F$ & 64 & 38 & 102 & & \\
\hline & $\mathrm{T}$ & 25 & 15 & 40 & 0.00 & ns \\
\hline \multirow[t]{2}{*}{ Idh } & $\mathrm{F}$ & 91 & 41 & 132 & & \\
\hline & $\mathrm{S}$ & 269 & 290 & 559 & 18.16 & $* * *$ \\
\hline \multirow[t]{2}{*}{$\mathrm{ma}$} & $\mathbf{F}$ & 35 & 11 & 46 & & \\
\hline & $\mathrm{S}$ & 43 & 69 & 112 & 8.52 & $* *$ \\
\hline \multirow[t]{2}{*}{ int } & $\mathrm{F}$ & 31 & 15 & 46 & & \\
\hline & $S$ & 53 & 59 & 112 & 5.56 & * \\
\hline \multirow[t]{2}{*}{$\mathrm{J} 1$} & $F$ & 23 & 8 & 31 & & \\
\hline & $\mathrm{T}$ & 18 & 22 & 40 & 5.87 & $*$ \\
\hline \multirow[t]{2}{*}{ Centromere } & $F$ & 86 & 16 & 102 & & \\
\hline & $\mathrm{T}$ & 27 & 13 & 40 & 6.48 & * \\
\hline \multirow{3}{*}{$\begin{array}{l}\text { Chromosome } \\
03\end{array}$} & $\mathrm{O}$ & & & & & \\
\hline & $\mathrm{F}$ & 76 & 26 & 102 & & \\
\hline & $\mathrm{T}$ & 20 & 20 & 40 & 7.77 & $* *$ \\
\hline \multirow[t]{2}{*}{$\mathrm{Me}$} & $F$ & 86 & 46 & 132 & & \\
\hline & $S$ & 193 & 236 & 429 & 16.3 & $* * *$ \\
\hline \multirow[t]{2}{*}{ Centromere } & $\mathrm{F}$ & 80 & 22 & 102 & & \\
\hline & $\mathrm{T}$ & 19 & 21 & 40 & 13.39 & $* * *$ \\
\hline
\end{tabular}

until recently (Brehm \& Krimbas, 1990). Inversion O3 is fixed in $D$. madeirensis. It has apparently been lost from $D$. subobscura, as two other gene arrangements are encountered in this species on each side of the triad of overlapping inversions of which $\mathrm{O} 3$ is the middle member, namely O ST and $\mathrm{O} 3+4$. The two species also differ in the regions near the centromere in chromsomes $\mathrm{E}, \mathrm{J}$, and $\mathrm{O}$ as well as for the tip of chromosome $\mathrm{J}$ : they show local non-pairing in the salivary gland chromosomes of their $\mathrm{F}_{1}$ hybrids (Krimbas \& Loukas 
1984). Allozymes at the Pept-3, ldh and $M e$ loci are diagnostic for the two species.

Antenna colour is a species-specific character, $D$. subobscura has dark and D. madeirensis has light antenna colour. This character is sex linked.

$n t, p p, p l, m a$ and int are visible mutants. It is undesirable to use more than two visible mutants at a time because viability is strongly affected. Some markers are more prone to display such an effect: this is the case for $c h$ (cherry eyes) and $c u$ (curled wings), both on chromosome $\mathrm{O}$ and used in a few crosses.

Unlike visible mutants, chromosomal markers may not affect the viability of hybrids and their backcross progeny but have the disadvantage that they can only be determined from the progeny of fertile males. Their segregation ratio can be studied in larvae of the backcross progeny. Electrophoretic markers and naturally occurring polymorphisms are adequate for following the segregation of chromosomes and their segments directly both in fertile and in sterile individuals of the backcross progeny.

Finally we would like to add the following information concerning the reciprocal cross of the one mentioned earlier. $D$. subobscura females cross with great difficulty to $D$. madeirensis males. This is the reason why this cross was reported not to have taken place in a previous publication (Krimbas \& Loukas 1984). This cross produces $F_{1}$ females (some fertile) and sterile males, in a distorted sex ratio ( 10 females to 175 males!). Many eggs from this cross do not hatch (M. Khadem \& C. B. Krimbas, unpublished data).

\section{Results}

\section{Sterility and the size of the testes}

Antenna colour was used to determine the origin of the $\mathrm{X}$ (=A chromosome) in all the backcross males (fertile and sterile). Table 2 shows a departure from a one-toone ratio in the segregation of madeirensis and subobscura $\mathrm{X}$ chromosomes in the male progeny in both backcrosses. This is apparently not the result of a segregation distortion in gamete formation by $F_{1}$ females: indeed in Table 3 a small sample of the larval female progeny of $F_{1}$ females is analysed and it does not show such a departure (in the first, second and third line, marked by $\mathrm{T}$ ). Thus the reason for this departure from the one-to-one ratio should be attributed to viability differences: males with a subobscura $\mathrm{X}$ in a madeirensis or hybrid cytoplasm and a mixed autosomal constitution (regardless of the origin of their $\mathrm{Y})$ are more viable than those with the same constitution but bearing a madeirensis $\mathrm{X}$.
In spite of these viability effects the genetics of male sterility can be investigated. The results can be summarized as follows: backcross males with incompatible sex chromosomes (Xmad/Ysub or Xsub/Ymad) and an unbalanced set of autosomes (regarding their origin) have reduced testes size without sperm and therefore are sterile. This is true for both reciprocal crosses. The reduced testes size does not generally appear in $F_{1}$ males which have incompatible $X-Y$ but a balanced sets of autosomes (also see discussion). In the case of backcross males some exceptions did occur. They can be easily interpreted if we accept that the antenna colour gene is located at the distal end of the chromosome and may recombine in $F_{1}$ females with the remaining part which bears the loci that affect testes size and sterility. If these 16 exceptions out of 363 males examined constitute crossover products they permit the estimation of the distance of the antenna colour from the sterility factors affecting the size of the testes as equal to $4.4 \pm 1.1 \mathrm{cM}$.

When there is compatibility (same origin) of the $\mathrm{X}$ and $\mathrm{Y}$, the male has testes of normal size. It may be sterile (immotile sperm) or fertile (motile sperm): backcross males with motile sperm represent 46 and 36 per cent, respectively, of the males with a compatible combination of the $\mathrm{X}$ and $\mathrm{Y}$ chromosomes in the crosses to madeirensis or subobscura males. The sterility in this case depends on the remaining genotype, that of the autosomes, as will be discussed below.

\section{The genetics of male hybrid sterility}

The genetic constitution of the backcross males is inferred by crossing them individually to virgin $s u b$ obscura females. Given enough time the backcross males mate. We did not observe any serious behavioural barrier in the courtship and mating; however, only fertile males produce progeny and their genotype can be assessed. In independent controls we gathered data on the genetic constitution of males from the same backcross but at the stage of third instar larvae or early pupae, in which salivary gland preparations are possible. This was done to check (for each chromosomal marker separately) the possibility of departure from a one-to-one ratio. A departure from this ratio apparently indicates the presence of viability effects. On the other hand the segregation ratio between fertile and sterile or total can be interpreted as being due to linkage between the markers and the loci that affect sterility. We can assess directly the genotype of the sterile backcross males for the electrophoretic and visible markers. The underlying assumption, when comparing the frequency of the fertile males in two genotypic classes (heterozgotes and homozygotes for a 
marker) is that they are equal when the marker does not affect fertility. Any departure would mean that the region identified by the marker includes genes that produce sterility. However, when specific interactions between viability and fertility are present this may not be the case (e.g. fertile individuals in one of the genotypic class tend to have a higher viability but not in the other class). Thus, theoretically, viability effects cannot be disentangled unambigiously from sterility; this weakness is inherent to this method, extraneous evidence is needed in order to obtain an unambiguous answer.

An inspection of Table 3 shows that in most of the cases there is no departure from a one-to-one segregation ratio for the markers used, which indicates the absence of differential viability. Exceptions are noted for the Me locus on chromosome $\mathrm{O}$, the centromere of chromosome J, for pl and Pept-3 on chromosome E. These markers and/or the chromosome segments marked by them may modify the viability of the backcross males in the genetic hybrid and backcross background. If we accept that the differences observed between the fertile and the sterile males (or the total) are due to sterility effects we can identify the sections of the autosomes, which by their presence reduce fertility (see Table 4). As a precaution we have excluded from our analysis other visible markers, cherry eyes and curled wings, which seemed to affect considerably the viabilities of the hybrids.

On the other hand we should note that in this respect our results have an obvious advantage, compared to those presented in similar studies concerning different pairs of closely related species of Drosophila: most of our markers are 'natural', found in wild populations of these species, or diagnostic of them. This is extremely important because laboratory mutants often, as we have already seen, display strong viability effects, especially in some interspecies hybrids, and no more than two may be used in the most favourable cases.

In Table 4 we report the results marker by marker. The fertile males (F) are compared either to their sterile brothers $(\mathrm{S})$, or to the total ( $\mathrm{T}$, fertile plus sterile) males from the same backcross (but in an independent sample to that of the fertile). In the extreme case concerning the cytological markers of chromosome $\mathrm{X}$ we used the female progeny from this backcross as a control in order to search for a departure from a one-toone segregation ratio (males being hemizygotes and unrecognizable). In this case, of course, the possibility of missing viability effects in adult males is real and the only supporting information in this respect is that presented in Table 2, concerning the sex-linked marker, white antennae. The control in case of the chromosomal marker of the $\mathrm{U}$ chromosome is missing.
In Table 4, we indicate for every marker the number of males with a homozygote (subobscura/subobscura) or hetreozygote (subobscura/madeirensis) genetic constitution in a chromosomal background that is mostly from subobscura origin and in a madeirensis (or hybrid) cytoplasm. For the markers of the single $X$ the control should be read as follows, sub for homozygotes subobscura/subobscura Xs and mad for subobscura/ madeirensis Xs, as the controls are female individuals.

All the chromosomes seem to have an effect on male hybrid sterility. The most obvious and preponderant influence is exerted by the sex chromosome which will be discussed later. There are autosomal segments which do not seem to influence fertility: the tip of the $\mathrm{J}$ chromosome, the region close to $p p$ and $p l$ in chromosome $\mathrm{E}$. In chromosome $\mathrm{E}$ the region that affects fertility is between Pept-3 and inversion E $1+2$. Pept-3 is located near the proximal breakpoint of inversion $E$ $1+2$ (but outside the inversion).

As the control for $U 1+2$ is missing, it is difficult to assess the effect of this chromosome. Prima facie it shows an important effect, except for the region near $n t$, which is located close to its tip (Table 4). The existence or magnitude of this effect can be merely an artifact. If it is real then it may be due to the fact that the largest part of this chromosomes in the reported crosses segregates almost as a single unit and thus there is either one sterility factor in this chromosome or the effects of many factors with a minor influence are consolidated ( $\mathrm{U} 1+2$ covers 66 per cent of the length of the entire chromosome).

The study of many markers spread along the entire chromosome J indicated the presence of more than one 'sterility unit'. $\mathrm{J}$ is a long chromosome and its genetic map is about $150 \mathrm{cM}$, the markers used are well spaced and many of them show a significant effect. It is possible, therefore, to postulate at least two sterility genes or units on this chromosome. The same could be said for chromosome $\mathrm{O}$, the longest of the chromosomes.

Thus the number of chromosomal regions that affect sterility is probably greater than five. Except for chromosome $X$, however, the data could also be interpreted to be produced by specific interactions between viabilities and fertilities, as has already been explained.

Are these regions interacting, or do they add their effects in a multiplicative way? Do fertile individuals bearing combinations of the sensitive markers/regions appear in the frequencies expected from random association? Independence of effect on sterility has been tested (using $\chi^{2}$ ), for pairs or triplets, of markers. They test whether fertile males carrying two or three markers simultaneously are less frequent than expected. The expected number is calculated by multiplying the frequencies of fertile males in each 
class with a single marker. The results will not be reported here in detail because nearly all comparisons indicate an absence of interaction. There are two exceptions, both of which indicate an interaction between the centromere of $\mathrm{O}$ and the region of $\mathrm{E}$ from the centromere to Pept-3. On the other hand, many such tests for an interaction between markers located on the same chromosome are significant; for E chromosome (centromere with Pept-3), J (1dh with tip) and $\mathrm{O}$ (Me with $\mathrm{O} 3$ ). Most of these cases can be explained as a result of linkage associations and do not provide grounds to invoke the existence of functional interactions. However, these results should be taken with some caution as they are based on the examination of markers (chromosomal and electrophoretical) in fertile individuals only.

\section{Discussion}

\section{The incompatibility of the $X$ and $Y$ chromosomes}

This incompatibility is important for determining testis size in the backcross progeny of the two species. The effect seems to be of an 'all or none' type: males with heterospecific sex chromosomes have reduced testes empty of sperm. This rule should be modified, however, because most of the $F_{1}$ males have normal testes of almost normal size but are sterile (sperm immotile). Thus the size reduction in the backcross males is achieved by an unbalanced genome, the $F_{1}$ males being in this respect balanced, with one set of autosomes from one species and another from the second species. On the contrary, the backcross males generally do not possess balanced sets of autosomes. If this interpretation is correct (and it seems to be the simplest and the most plausible) the autosomes interact with the heterospecific $\mathrm{X}-\mathrm{Y}$ combination to produce the reduced size of the testes.

Approximately the same mechanism is reported for another pair of very closely related species, D. pseudoobscura and D. persimilis (Dobzhansky, 1951). In one backcross progeny, that of $F_{1}$ females crossed to pseudoobscura males, there is a clear bimodality of phenotypes; two groups are recognized, those of reduced testes and the near normal ones; this resembles the present case closely $(\mathrm{X}-\mathrm{Y}$ incompatibility with unbalanced autosome sets). However this does not apply to the other backcross (i.e. $F_{1}$ females to persimilis males).

Male hybrid sterility is not only expressed by the presence of reduced testes: the presence of the immotile sperm in normal size testes is another manifestation. This is the case for some of the $F_{1}$ males from the cross of $D$. subobscura females and $D$. madeirensis males.

All heterospecific $\mathrm{X}-\mathrm{Y}$ males are sterile, $\mathrm{F}_{1}$ as well as backcross males, regardless of their autosomal constitution. No fertile male is found to have a madeirensis $\mathrm{X}$ chromosome with a subobscura $\mathrm{Y}$ and in a predominantly subobscura background. We also have some data (not included in Table 3) concerning the reciprocal backcross of $F_{1}$ females to madeirensis males: here too the same rule is applied, there are no fertile males with a subobscura $\mathrm{X}$ chromosome in combination to a madeirensis $\mathrm{Y}$ in a preponderantly madeirensis genetic background. The sample is very small in this case (only six individuals). However, these results are consistent with the ones reported in Table 2 .

This is also known to be the situation in hybrids of $D$. pseudoobscura and D. persimilis (Orr, 1987). The $\mathrm{X}-\mathrm{Y}$ incompatible combinations have immotile sperm. Both species pairs also have bidirectional sterile $F_{1}$ male hybrids, and both comprise species belong to the obscura group of the subgenus Sophophora. The same mechanism also holds for two species, $D$. simulans and D. mauritiana, which belong to the melanogaster group (Coyne 1984, 1985).

\section{The $X$ chromosome}

This chromosome has the largest effect of any of the chromosomes in determining male sterility. All parts of this chromosome, except for a small section near its tip (inversion $16 \mathrm{BCD}$ ), exert a strong effect on the fertility of the backcross males. Inversion 16BCD, which covers 5 per cent of the A chromosome's length, is found in $\mathbf{1 1 . 5}$ per cent of the fertile male. We have interpreted this as being due to recombination, inversion $16 \mathrm{BCD}$ being at a distance of $11.5 \mathrm{cM}$ from the sterility factors on this chromosome. Following the same interpretation antennae colour, a sex-linked gene recombines with the sterility factors at a frequency of 4 per cent. Both markers are apparently located at the same end, the tip, of the chromosome (the two species differ by one inversion located very near the centromere end of the $\mathrm{X}$ chromosome, inversion MAD 1, which never recombines with the sterility genes). If this is so, the region free from sterility factors could not be any longer than 15 per cent of the chromosome's length. This estimation is based on the length of $16 \mathrm{BCD}$ compared to the total length of the $\mathrm{X}$ chromosome (both measured from the cytological map). The total length of the $\mathrm{X}$ chromosome is about $260 \mathrm{cM}$ (Bird, 1947). A formal proof is not available at the moment but all the evidence suggests the presence of more than one sterility factor on the X chromosome.

Although there is evidence that several mechanisms 
develop in different cases or in different species groups for building a genetic barrier between closely related species (Coyne, 1984, 1985; Vigneault \& Zouros, 1986; Zouros et al., 1988 and Orr, 1987; 1989), in all cases studied in detail so far, the sex chromosomes are involved and play a preponderant role, which fits with the theoretical explanation suggested by Charlesworth et al. (1987). These authors showed that the frequent effect of the chromosomes on the viability and fertility of hybrids is due to the substitution of recessive or partially recessive, but selectively favourable mutations being fixed more rapidly for $\mathrm{X}, \mathrm{Y}$ or $\mathrm{X} / \mathrm{Y}$-linked loci than for the autosomes. It should be mentioned that all the reported cases in Drosophila are in accordance with Haldane's rule (1922) to a different degree and represent the first stage of postzygotic isolation (Coyne \& Orr, 1989b).

\section{The autosomes}

The follow-up of the chromosomal and electrophoretic markers provides an obvious advantage to that of visible mutants: the former are less likely to display a viability or fertility effect of their own than the latter. Using 16 different autosomal markers, the majority of them are chromosomal and electrophoretic, we were able to follow different regions of the four autosomes in the backcross males. At first sight all the autosomes seem to possess sections that affect the fertility of the backcross males. We have already explained how such a minimum number of autosomal factors could be estimated: one on the $\mathrm{E}$ chromosome, probably two on $\mathrm{J}$ and $\mathrm{O}$ chromosomes and one gene on the $\mathrm{U}$ chromosome; the presence of at least six genes is suggested. These genes could not possibly produce an 'all or none' effect; complete male sterility. In the case of six factors that segregate nearly independently (in view of the great length of the maps of the autosomes, Krimbas, 1990), the frequency of the sterile backcross males, with those with a compatible $\mathrm{X}-\mathrm{Y}$ combination, would be nearly 2 and 6.25 per cent for four independent factors (the number of independently segregating autosomes). The actual frequency of sterile males varies between 36 and 46 per cent (Table 2). Thus the presence of only one (hardly two) such factor(s) is sufficient to cause sterility although at least six factors are able to contribute to it. Of course, as we have already pointed out, another explanation is also possible: the presence of viability effects, i.e. in specific genotypes the existence of interactions of viability with the fertility of their carriers. This could lead to similar results to those observed in our study. All these types of experiment have an inbuilt disadvantage, which has been overlooked in several published reports.

\section{Maternal effect}

The data presented suggest the existence of a maternal effect on the viability of the $F_{1}$ females alone. These have the same genotype but are viable only in a madeirensis cytoplasm and mostly inviable in a subobscura cytoplasm. A maternal effect is probably present, but to a lesser extent, in the $F_{1}$ males. That is to say that only a few individual flies are produced in each trial of mass crossing $D$. subobscura female to $D$. madeirensis male. This cross produces many fertilized eggs but most embryos die in the early stage of their development (M. Khadem \& C. B. Krimbas, unpublished data). The ones that develop further and reach adulthood are a few sterile males and even less females. These females have a low viability and usually die a few days after hatching. Only one out of a total of 10 females produced, after many trials, lived long enough to be able to produce progeny. Their sterile brothers had a normal life expectancy. Thus heterogametic males are sterile and viable and the homogametic females are partially fertile but much less viable. As far as viability is concerned this is in contradiction to Haldane's rule. The reciprocal cross, on the other hand, is in accordance with it. In two cases in the literature the genetic basis of female inviability has been analysed, those of $D$. montana crossed to $D$. americana (Patterson \& Griffen, 1944), and of $D$. mulleri to $D$. aldrichi (Crow, 1942). Both cases are exceptions to Hadane's rule: only $F_{1}$ females are affected. Thus the suggestion of Coyne \& Orr (1989a) that sterility and inviability evolve at similar rates and both are a by-product of similar genetic processes, should be taken lightly.

We should finally add that the viability of the backcross males is also strongly affected by the type of $\mathbf{X}$ chromosome that they carry. Backcross males with a madeirensis $\mathrm{X}$ on a hybrid background are less viable than those that carry a subobscura $\mathrm{X}$ (Table 2.) This suggests an incompatibility between a medeirensis $\mathrm{X}$ with autosomes of mixed origin.

\section{Conclusions}

It is evident from the present data, and those published by other authors, that the genetic system underlying postzygotic isolation in Drosophila species is similar. There are few cases that depart from the general pattern but they can be interpreted as a result of mechanism(s) that are build up after the occurrence of initial isolation.

The presence of a general pattern is not proof that the same genes have been mobilized in all the cases. So far, only a few speciation genes have been identified and further work is needed in this respect. 


\section{Acknowledgements}

We would like to thank the Alexander Onassis Foundation, Mrs Annette Sclumberger and La Foundation Treilles for financial support and Mrs Georgia Kolia and $\mathrm{Mr}$ Vassily Alevizos for technical assistance.

\section{References}

BARTON, N. H. AND CHARLSWORTH, B. 1984. Genetic revolutions, founder effects and speciation. Ann. Rev. Ecol. Syst, 15, 133-164.

BIRD, M. J. 1974. The genetics and cytology of Drosophila subobscura. Further data on sex-linked mutants. Ph.D. Thesis, University College, London.

BREHM, A. AND KRIMBAS, C. B. 1990 . Evolution of the obscura group Drosophila species. III. Phylogenetic relationships in the subobsura cluster based on homologies of chromosome A. Heredity, 65, 269-275.

CARSON, H. L. AND TEMPLETON, A. R. 1984. Genetic revolutions in relation to speciation phenomena: the founding of new populations Ann. Rev. Ecol. Syst., 15, 97-131.

CHARLESWORTH, B., COYNE, J. AND BARTON, N. 1987. The relative rates of evolution of sex chromosomes and autosomes. Am. Natur., 130, 113-146.

COYNE, J. A. 1984 . Genetic bases of male sterility in hybrids between two closely related species of Drosophila. Proc. Natl Acad. Sci., USA ., 81, 4444-4447.

COYNE, J. A. 1985. The genetic basis of Haldane's rule. Nature, 314, 736-738.

COYNE, J. A. AND ORR, H. A. 1989a. Patterns of speciation in Drosophila. Evolution, 43, 326-381.

COYNE, J. A. AND ORR, H. A. 1989 b. Two rules of speciation. In: Endler, J. A. and Otte, D. (eds), Speciation and its Consequences. Sinaure Sunderland, MA, 180-207.

CROW, J. F. 1942. Cross fertility and isolating mechanisms in the Drosophila mulleri group. Univ. Texas Publ., 4228, 53-67.
DOBZHANSKY, TH. 1936. Studies on hybrid sterility. ii. Localization of sterility factors in Drosophila pseudoobscura hybrids. Genetics, 21, 113-135.

DobZhansky, TH. 1951. Genetics and the Origin of Species. 3rd edn. Columbia University Press, New York.

HALDANE, J. B. S. 1922. Sex ratio and unisexual sterility in animal hybrids. J. Genetics, 12, 101-109.

KRIMBAS, C. B. 1991. Drosophila subobscura: Biology, genetics and inversion polymorphism. In: Krimbas, C. B. and Powell, J. R. (eds), The Drosophila Inversion Polymorphism. CRC Press, Boca Raton FA (in press).

KRIMBAS, C. B. AND LOUKAS, M. 1984. Evolution of the obscura group Drosophila species. i. Salivery chromosomes and the quantitative characters in D. subobscura and two closely related species. Heredity, 53, 469-482.

NAVIERA, H. AND FONTDEVILA, A. 1986. The evolutionary history of Drosophila buzzatii. XII. The genetic basis of sterility in hybrids between $D$. buzzatii and its sibling $D$. seridofrom Argentina. Genetics, 114, 841-857.

ORR, H. A. 1987 . Genetics of male and female sterility in the hybrids of Drosophila pseudoobscura and D. persimilis. Genetics, 116, 555-563.

ORR, H. A. 1989. Genetics of sterility in hybrids between two subspecies of Drosophila. Evolution, 43, 180-189.

PATTERSON, J. T. AND GRIFFEN, A. B. 1944. A genetic mechanism underlying species isolation. Univ. Texas Publ., 4445, 212-223.

VIGNEAULT, G. AND zouros, E. 1986. The genetics of asumetrical male sterility in Drosophila mojavensis and Drosophila arizonensis hybrids: Interaction between the $\mathrm{Y}$ chromosome and autosomes. Evolution, 40, 1160-1170.

WHITE, M. J. D. 1978. Modes of Speciation. WH Freeman, San Francisco.

WRIGHT, s. 1982 . The shifting balance theory of macroevolution. Ann. Rev. Genet., 16, 1-19.

zouros, E., LOFDAHL, K. AND MARTiN, P. A. 1988. Male hybrid sterility in Drosophila: Interactions between autosomes and sex chromosomes in crosses of $D$. mojavensis and $D$. arizonensis Evolution, 42, 1321-1331. 